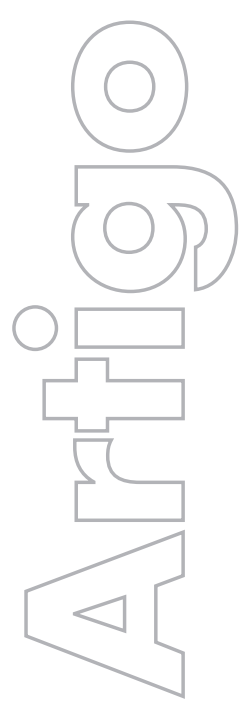

Articulação entre múltiplas escalas geográficas: lógicas e estratégias espaciais de empresas

\author{
Maria Encarnação Beltrão Sposito \\ Unesp
}

Eliseu Savério Sposito

Unesp

revista

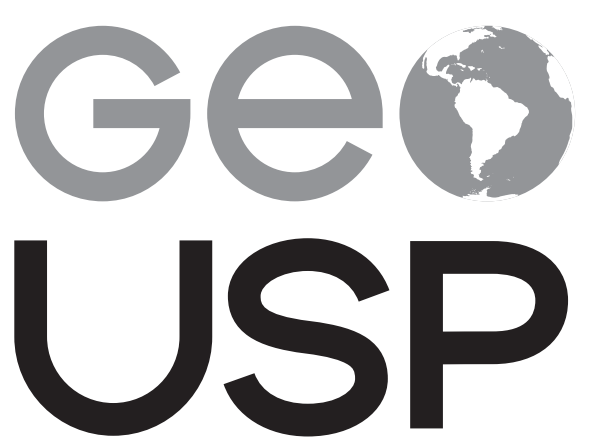

espaço e tempo

Volume $21 \cdot n^{\circ} 2(2017)$
Como citar este artigo:

SPOSITO, M. E. B.; SPOSITO, E. S. Articulação entre múltiplas escalas geográficas: lógicas e estratégias espaciais de empresas. Geousp - Espaço e Tempo (Online), v. 21, n. 2, p. 462-479, agosto. 2017. ISSN 2179-0892.

p. $462-479$

Disponível em: < http://www.revistas.usp.br/geousp/ article/view/131655>. doi: 10.11606/issn.2179-0892. geousp.2017.131655.

\section{(c) $(1) \circledast$}

Este artigo está licenciado sob a Creative Commons Attribution 4.0 License. 


\title{
Articulação entre múltiplas escalas geográficas: lógicas e estratégias espaciais de empresas
}

\section{Resumo}

No atual período, marcado por formas de produção e consumo associadas ao pós-fordismo e pela constituição social e política do neoliberalismo, empresas de diferentes portes econômicos e abrangências espaciais baseiam suas decisões sobre a localização de seus estabelecimentos e a conformação de seus mercados e áreas de atuação segundo diferentes escalas geográficas. De um lado, a articulação entre lógicas econômicas e espaciais e, de outro, estratégias espaciais das empresas são apresentadas aqui no contexto do capitalismo contemporâneo e da conformação de redes de lojas comerciais que se sustentam em redes urbanas, mas também transformam suas configurações e os papéis de várias cidades nessa estrutura espacial de escala interurbana. Tomamos como referência empírica a lógica econômica e espacial de algumas empresas e a estratégia espacial de outras para mostrar o que é geral e o que pode ser apreendido como particular e singular nas tendências analisadas.

Palavras-chave: Lógicas econômicas. Estratégias espaciais. Escalas geográficas. Comércio. Consumo.

\section{Articulations amongst multiple geographical scales: logics and spatial strategies of companies}

\begin{abstract}
In current times, marked by forms of production and consumption associated with post-fordism, and the social constitution and neoliberal policy, companies of different economic sizes and spatial scopes base their decision-making to the location of their establishments and to conform their markets and areas according to different geographical scales. The link between, on the one hand, economic and spatial logic and on the other, spatial strategies of companies is presented in this text, in the context of contemporary capitalism and formation of shop networks that rely on urban networks as a condition of acting, but also transform their settings and the roles of various cities in these spatial structures of interurban scale. We take, as empirical reference, the
\end{abstract}


economic and spatial logic of some companies and other's spatial strategies to show what is generally and what can be understood as particular and unique in the analyzed trends.

Keywords: Economic logics. Spatial strategies. Geographical scales. Trade. Consumption.

\section{Introdução}

Neste texto, tratamos das lógicas e estratégias espaciais das grandes empresas que operam no setor comercial, mas consideramos fundamental que essa perspectiva não seja independente da articulação que há entre elas e as práticas espaciais dos citadinos, pois estas não são apenas reflexos daquelas, mas também as reorientam.

Esse destaque é importante porque a reflexão que apresentamos, em torno das lógicas e estratégias espaciais das empresas, decorre de projeto de pesquisa que vem sendo desenvolvido pelo Grupo de Pesquisa Produção do Espaço e Redefinições Regionais (GAsPERR), intitulado Lógicas econômicas e práticas espaciais contemporâneas: cidades médias e consumo ${ }^{1}$ havendo, portanto, para nós, uma intrínseca relação entre os modos de tomar decisões das empresas comerciais e as práticas espaciais de seus consumidores, mesmo que estas não sejam tratadas neste texto. Nosso recorte analítico, nesta pesquisa, não tem o comércio e o consumo como objetos da investigação, mas toma-os como caminho para compreender como as grandes empresas comerciais e de serviços, de capital nacional e internacional, estão escolhendo as cidades que têm papéis regionais para se instalar e de que modo tais escolhas reorientam e são reorientadas pelas práticas espaciais dos citadinos. ${ }^{2}$

Neste texto, buscamos distinguir lógicas econômicas e espaciais de estratégias espaciais, na direção de analisar as escolhas espaciais na rede urbana brasileira para valorizar não apenas as tendências gerais do período atual, mas, sobretudo, as particularidades dos processos gerais de produção capitalista do urbano e da cidade.

Em termos metodológicos, tratamos das grandes empresas porque são elas que, em suas lógicas e estratégias espaciais, articulam múltiplas escalas geográficas de modo mais intenso, não apenas porque ligam cidades distantes entre si, mas porque o fazem redefinindo seus papéis e posições nas redes urbanas às quais pertencem. ${ }^{3}$ Essa constatação é muito importante, pois nossa pesquisa volta-se ao estudo de cidades que não são espaços metropolitanos e/ou não ocupam posição hierárquica importante no sistema urbano global, as quais estão, portanto, mais suscetíveis ao comando de empresas sediadas nos polos de comando de uma economia progressivamente mundializada, as quais passaram e passam a atuar nestas cidades.

1 Projeto desenvolvido com apoio da Fundação de Amparo à Pesquisa do Estado de São Paulo (Fapesp).

2 Na pesquisa supracitada, nosso foco recai sobre: os processos de reestruturação urbana (Soja, 1993), que refletem a redefinição dos papéis urbanos na divisão interurbana do trabalho; na reestruturação das cidades (Sposito, 2006), que se revelam pelo rompimento da lógica "centro-periferia" tout court que, anteriormente, era a que orientava a estrutura urbana das cidades, pois há uma profunda transformação na divisão econômica e social dos espaços urbanos estudados por nós.

3 As grandes empresas, ao fazerem suas escolhas locacionais, alteram a estrutura espacial das cidades onde se instalam, ainda que esse tema não seja tratado neste texto, mas vem sendo objeto de nossa atenção e de outros pesquisadores do grupo, em outras publicações. 
Em relação à rede urbana, a importância das cidades médias, estrato da rede urbana que vimos tomando com objeto de pesquisa e reflexão, tem crescido nas duas últimas décadas no Brasil. Elas são elementos significativos dessa rede para a indução de modos de consumo e têm sido objeto de escolha das grandes empresas de modo cada vez mais intenso. A combinação das lógicas com as estratégias das empresas é comprovada pelos dados empíricos das cidades exploradas em várias dimensões, escalas espaciais e temporais urbanas.

As hipóteses que levantamos na pesquisa exigiram a discussão dos conceitos de lógica e de estratégias espaciais, que desenvolveremos na segunda e terceira seções deste texto. Antes, na primeira seção, vamos oferecer um quadro geral com elementos que nos parecem fundamentais para se compreender a urbanização e as cidades contemporâneas.

\section{O capitalismo contemporâneo e suas especificidades}

Muita literatura está disponível desde que, em meados da década de 1970, o desenvolvimento do capitalismo enfrentou uma nova crise, parte de seu próprio movimento de redefinição das bases sobre as quais esse modo de produção reproduz-se e se recria. Vamos nos concentrar nas ideias de poucos autores para dar mais foco à década mais recente. Com essa escolha, pretendemos contextualizar o tema de nosso artigo a partir de avanços teóricos que almejam ultrapassar a simples constatação da crise e de seu perfil, para chegar a uma análise mais aprofundada, feita por eles. Essa perspectiva revela que as alterações em curso se constituem de transformações profundas que vão além dos estritos ajustes necessários à superação das fases em que a taxa de lucro declina e os níveis de reprodução capitalista se estreitam.

Dardot e Laval, na edição brasileira de seu livro (2016), publicado originalmente na França em 2009, nomeiam o prefácio de "um sistema pós-democrático", revelando desde esse título o sentido geral que a obra deseja revelar e frisam:

[...] é errado dizer que estamos lidando com o "capitalismo" sempre igual a ele mesmo, e com suas contradições, que inevitavelmente levariam à ruína final. [...] capitalismo é indissociável da história de suas metamorfoses, de seus descarrilamentos, das lutas que o transformam, das estratégias que o renovam. O neoliberalismo transformou profundamente o capitalismo, transformando profundamente as sociedades. (Dardot; Laval, 2016, p. 7, grifo nosso)

Esses autores mostram que não estamos lidando apenas com mudanças na base econômica do sistema, apoiadas por um conjunto de medidas políticas, mas estamos diante de alterações sociais decorrentes, sobretudo, do fato de que a ação coletiva se tornou mais difícil, face ao regime de concorrência que se estabeleceu em todos os níveis. Para eles, a concorrência interindividual define novos modos de subjetivação, os quais revelam, a nosso ver, a profundidade das alterações concernentes ao nosso tempo e justificam o título do livro (A nova razão do mundo. Ensaio sobre a sociedade neoliberal) e não apenas uma análise da economia neoliberal. ${ }^{4}$

4 Os autores explicitam claramente essa posição ao afirmar que "[...] a originalidade do neoliberalismo está no fato de criar um novo conjunto de regras que definem não apenas outro 'regime de acumulação', mas também, mais amplamente, outra sociedade" (Dardot; Laval, 2016, p. 24). 
A principal linha de argumentação dos autores é de que o "[...] neoliberalismo não destrói apenas regras, instituições, direitos. Ele também produz certos tipos de relações sociais, certas maneiras de viver, certas subjetividades" (Dardot; Laval, 2016, p. 16, itálico dos autores). Esta remodelação da subjetividade, como eles propugnam, tem suas raízes no plano político ("a conquista do poder pelas forças neoliberais"), no econômico ("o rápido crescimento do capitalismo financeiro globalizado") e no social ("a individualização das relações sociais às expensas das solidariedades coletivas, a polarização extrema entre ricos e pobre" e o "surgimento de um novo sujeito, o desenvolvimento de novas patologias psíquicas").

$\bigcirc$ "homem neoliberal" a que estes autores fazem referência e caracterizam tem similitude e interfaces com o "homem endividado", descrito e analisado por Lazzarato (2013, p. 30, grifo nosso), em seu Ensaio sobre a condição neoliberal, e que compreende "a dívida como o motor econômico e subjetivo da economia contemporânea". Lazzarato (2013, p. 101) mostra que, na gestão da dívida, encontra-se a essência da luta de classes no século XXI pois, para ele, ela constitui "[...] la relación de poder más desterritorializada y general, a través de la cual el bloque de poder neoliberal organiza su lucha de clases" (Lazzarato, 2013, p. 103).

Estamos de acordo quanto ao caráter desterritorializado dessa relação de poder - a dívida - entretanto, devemos nos perguntar como as empresas se territorializam, com quais lógicas e estratégias espaciais escolhem suas localizações e, por meio delas, vendem bens e serviços, juntamente com a dívida que se torna necessária para o consumo em larga escala, via crédito. Em outras palavras, se a dívida pode ser vista como desterritorializada, o consumo, razão importante, ainda que não única do endividamento, ${ }^{5}$ precisa do território para se realizar em grande escala.

Esse aspecto é importante porque o crédito vem sendo, no caso brasileiro, o caminho, por meio do qual, as condições de ampliação do consumo vêm se consubstanciando entre os mais pobres, aqueles que aumentaram, de modo mais significativo, sua capacidade de compra. A classe trabalhadora tem tido maiores condições de consumo no Brasil, a partir dos anos 2000, com as políticas sociais do governo federal, nos períodos presidenciais de Luís Inácio da Lula Silva e Dilma Rousseff, bem como em decorrência do crescimento do salário mínimo e da taxa de emprego. ${ }^{6}$ Isto não significa, entretanto, a constituição de uma efetiva inclusão social, pois se trata muito mais de ampliação da inclusão econômica, nos termos descritos por J. Souza (2006, p. 185), ao tratar do caráter de nossa modernização periférica, altamente segmentada no acesso ao mercado ou aos benefícios da esfera pública, pois como ele afirma "[...] no âmbito das sociedades periféricas [...] a desigualdade social em todas as suas dimensões assume proporções e formas particulares virulentas" (Souza, J. 2006, p. 178).

5 Essa questão levanta um debate importante no mundo atual: parte do endividamento da sociedade decorre de sua necessidade de prover necessidades efetivas (e não apenas satisfazer desejos), como a aquisição da casa própria e o acesso ao ensino básico, médio ou superior, pois grande parte das dívidas das famílias é decorrente desse tipo de "consumo", mediada ou não pelo financiamento público. Essa é uma diferença substancial entre os efeitos da nova ordem capitalista no "centro" do sistema e em sua "periferia".

6 Esse quadro vem mudando desde 2013. Logo depois da crise internacional de 2009, o governo brasileiro foi capaz de conter os reflexos dela na economia nacional, com investimentos públicos em ramos da atividade geradores de emprego, como é o caso da produção imobiliária. Atualmente, o desemprego aumenta (ainda que esteja muito abaixo dos picos alcançados nos anos de 1990) e tem havido relativa contração da capacidade de consumo. Isso denota que a crise que levou ao impeachment da presidente do Brasil (agosto de 2016) não é apenas política, mas tem nuances econômicas e é, sobretudo, social, visto que as elites e a classe média, em grande parte, não estiveram e não estão satisfeitas com os investimentos públicos maiores em políticas de apoio à melhoria da condição de vida dos mais pobres. 
Esses argumentos reforçam a necessidade de se dar mais importância às especificidades das formas de articulação das economias periféricas ao capitalismo internacional e, especialmente, reforça a importância de se discutir a estruturação das redes urbanas e os papéis das cidades, segundo sua posição nessa estrutura e as relações que estabelecem entre si e com cidades de outras redes. Hoje este processo, mais que antes, está altamente influenciado pelas escolhas espaciais das grandes empresas (seja no que se refere ao setor comercial, objeto deste artigo, como em outros segmentos como o ramo bancário e o imobiliário, para citar alguns entre os mais importantes).

A preocupação com as especificidades está presente na formulação de Hidalgo e outros (2016), para os quais é usual na América Latina o predomínio da importação de teorias elaboradas para o contexto anglo-saxão, muitas vezes com ênfase no social e pouca atenção com sua dimensão espacial. Isso revela que é uma limitação aceitar:

[...] la aplicación de un discurso teórico elaborado para contextos territoriales del capitalismo avanzado en ámbitos como el latino-americano donde el neoliberalismo ha sido implantado de manera profunda, violenta y sin paisajes regulatorios social demócratas pretéritos, produce distorsiones que no corrigen por quienes lo importan de manera acrítica (Hidalgo et al., 2016, p. 26).

Esses autores frisam que, como parte do processo de desenvolvimento do capitalismo, o neoliberalismo tem um desenvolvimento geograficamente desigual, porque se implanta multidirecional e multiescalarmente, com formas genéricas de regular o mercado, mas isso ocorre em diversos lugares, territórios e escalas que têm marcos regulatórios e institucionais diversos entre si. Isso deve estimular, para eles, a avançar refletindo sobre o neoliberalismo não apenas como modo de regulação política, mas como uma ideologia ativa de produção e reprodução do espaço (Hidalgo et al., 2016, p. 27-30).

Nas próximas duas seções deste texto, ao tratarmos das lógicas econômicas e espaciais e das estratégias espaciais, esperamos contribuir para mostrar particularidades da geometria que resulta das escolhas locacionais das empresas, oferecendo alguns elementos para se avaliar como num país capitalista, relativamente periférico, a força dos grandes capitais reforça ou redefine estruturas das redes urbanas.

\section{Lógicas econômicas, lógicas espaciais}

A palavra lógica tem conteúdo polissêmico. Vem do grego logos e pode tanto significar o modo como usamos o raciocínio para desenvolver uma atividade, como quer dizer estudo normativo e, em certa medida, filosófico do próprio raciocínio. No plano filosófico, a lógica se ocupa do tratamento das formas de raciocínio que orientam a formulação de hipóteses, levam a inferências, deduções e induções, dão sentido aos caminhos do pensamento e que visam, em princípio, atestar que determinadas operações intelectuais e, portanto, científicas têm acuidade.

Se nos aproximamos da matemática, campo de abstração que pode subsistir sem a comprovação empírica, a lógica também é responsável pelos modos de condução do pensamento e, neste âmbito, tanto quanto no filosófico, a base da palavra lógica está no raciocínio. Se ficarmos com o uso que o senso comum atribui a esta palavra - lógica - podemos pensar em 
frases como "a lógica das mulheres"; "a lógica dos jovens", "a lógica dos loucos", "a lógica do trânsito", "a lógica das cidades" ou em tantas lógicas como grupos, sistemas, instituições, entidades sociais ou espaciais se organizam, mas estaremos buscando, assim, compreender como tal grupo, tal sistema, tal instituição ou entidade funciona do ponto de vista das matrizes de raciocínio que os conduzem. Estamos ainda admitindo que pode haver várias lógicas, já que chegamos a reconhecer que até mesmo os "loucos" devem ter suas razões para agir de um modo ou de outro, ainda que nem sempre sejamos capazes de desvendá-la, como aliás não chegamos a desvendar completamente as múltiplas lógicas que orientam a estruturação das redes urbanas e a produção do espaço urbano, razão pela qual convém sempre observar suas particularidades espaciais e suas mudanças no decorrer do tempo

Ao admitir que há várias lógicas e existe até mesmo as que são pouco verossímeis, está implícito que as lógicas podem ser completamente racionais, mas nem sempre o são, ou seja, podem resultar de uma combinação entre objetividade e subjetividade. Isso não significa que não desejemos, ainda (em relação aos loucos ou às cidades ou...), buscar suas razões ainda que reconheçamos que nem sempre elas são de caráter objetivo.

As empresas fazem suas escolhas espaciais estudando, mensurando, prospectando, projetando, avaliando e reavaliando. Buscam as evidências de que podem pesar todas as variáveis e que farão a opção certa, embora haja inúmeros estudos que mostram que o perfil de quem toma a decisão, o seu senso de oportunidade e até seu feeling são capazes de pesar e escolher na hora certa. Erram algumas vezes, mas impera o desejo e predominam as ações que privilegiam as racionalidades na escolha.

O sentido dado por nós à expressão lógicas, quando a utilizamos para nomear as ações das empresas, é o econômico. No entanto, ele não se viabiliza sem ações espaciais e políticas. Especialmente em relação ao espaço, consideramos que ele não é apenas resultado das demais dimensões da vida social (econômica, política, cultural etc.), mas também plano de suas determinações (e não determinismos), pois estamos falando de um período da história do capitalismo em que o consumo, do ponto de vista dos circuitos econômicos, conduz e orienta a produção do espaço, sendo esta produção um dos meios importantes para a reprodução do sistema.

As lógicas econômicas e espaciais das empresas têm, assim, a capacidade de reafirmar a hierarquia ou a posição que as cidades ocupam na rede urbana, não como tamanho demográfico, mas como combinação entre situação geográfica e nível de complexidade de seus papéis e funções. Quando nos reportamos a essas lógicas, reconhecemos, portanto, de uma dialética hegeliana, pois o movimento entre os contrários não produz a sua superação, mas apenas a novidade que reforça o "instinto geral do sistema" (como metáfora), porque o sentido das lógicas é alcançar o encadeamento dos acontecimentos ou elementos de modo efetivo, sem gerar, sempre, a contradição que poderia levar à sua superação. Por esta razão, as lógicas das empresas buscam também encontrar nos interstícios da ação social, nas suas não realizações, os caminhos para ampliar, por meio do consumo, o alcance espacial de sua reprodução econômica.

Assim, embora num primeiro momento, possamos pensar no primado do econômico, logo percebemos que, refletindo o sentido geral do neoliberalismo, as empresas atuam alterando e sendo alteradas pelas dimensões política e social, fazendo este movimento em múltiplas escalas espaço-temporais. 
Se aceitarmos essas características, concordamos com a ideia de que são capazes de inovar, de romper com as configurações que desenharam em dado interregno de tempo em determinado espaço, para se relocalizarem, obedecendo à hierarquia urbana, mas negando-lhe quando Ihes convêm. $O$ desenvolvimento recente do modo capitalista de produção mostra isso, na passagem do fordismo para o pós-fordismo, ou para o que podemos considerar o período contemporâneo da mundialização da economia, caracterizado pelas ações neoliberais. Tal passagem é um processo econômico, político e social que não poderia se realizar, como se deu, não fosse essencialmente espacial, não tivesse se efetivando por meio da aceleração do tempo, expressão cunhada por Milton Santos, e sido comandado, em primeiro plano, pelas demandas do consumo.

Assim, embora haja lógicas espaciais próprias das empresas, articuladas a lógicas econômicas, que visam, em princípio, diminuir custos e ampliar as bases territoriais de sua ação, sobretudo quando são comerciais e de serviços, uma vez que isso é sinônimo de crescimento potencial do mercado, elas não fazem sempre as mesmas escolhas, em todas as situações geográficas em que se inserem, daí a necessidade de reconhecer que as lógicas são gerais, mas que há estratégias espaciais que são colocadas em prática em cada contexto.

O substantivo "lógica" pode ganhar estatuto científico associado ao adjetivo "espacial". As lógicas espaciais que orientam as escolhas de localização das empresas são, como primeira aproximação: geométricas (no sentido da métrica, da medida, da configuração espacial que desenham com suas escolhas); imperiosas (porque se impõem aos interesses sociais e às relações políticas e os submetem, ainda que nunca se estabeleçam como lógica única); dominantes (porque expressam os interesses dos grandes capitais sobre os espaços, articulando diferentes dimensões espaciais locais em múltiplas escalas geográficas, alcançando a internacional); e cartesianas (mesmo que e porque, com seu conteúdo instrumental, sejam capazes de encontrar nos interstícios da ação social, nas suas não realizações, os caminhos para ampliar, por meio do consumo, o alcance espacial da reprodução econômica das empresas).

Como segunda aproximação, podemos afirmar que essas lógicas (enfatize-se seu caráter econômico ou espacial) são articuladas segundo alguns pares contraditórios. Elas podem ser lidas por meio das noções de universal e particular, racional e tradicional, unidade moderna e diversidade dos costumes (Lipovetsky; Serroy, 2010). E esses últimos pontos - unidade moderna e diversidade de costumes - mostram que elas são também essencialmente políticas e sociais.

Como estamos, neste texto, abordando as lógicas para compreender o consumo na sociedade em que o neoliberalismo vai dominando as ações, pouco a pouco e de maneira evidente e inexorável, esses pares dialéticos ganham sentido quando são enfocados empiricamente. $\bigcirc$ universal se expressa na forma como se articulam os diferentes tipos de capital em suas diferentes escalas de atuação, seja num país ou ultrapassando fronteiras por meio da legislação e das facilidades estabelecidas pelo sistema financeiro.

Esses pares contraditórios são, em sua essência, pilares onde se apoiam as lógicas econômicas e as espaciais em curso no âmbito do desenvolvimento do capitalismo. No ramo comercial, com ênfase, o que não significa que não possamos generalizar estas constatações a outros ramos econômicos, há algumas lógicas que prevalecem, algumas econômicas e outras espaciais, num período de mundialização da economia e de diminuição das barreiras nacionais ao comércio internacional. Podemos fazer referência às principais entre elas. 
Começamos pela concentração econômica compreendida como a capacidade que as empresas têm de ampliar seus capitais, face às possibilidades de sua reprodução capitalista; em outras palavras, é crescente o aumento do capital nas mãos de algumas empresas, gerando maior presença delas, relativamente às pequenas, se tomamos como referência o que ocorreu nos últimos trinta anos no Brasil. Com base no ranking das cinquenta maiores empresas que operam no país, a partir do levantamento realizado pela revista Exame (2006), série Maiores e MeIhores, verificamos que em 2005 (ranking 2006), havia três dedicadas ao comércio varejista, ${ }^{7}$ que perfaziam um total de 15.022 milhões de dólares em vendas. Dez depois, em 2015 (ranking 2016), eram seis empresas ${ }^{8}$ que totalizavam 26.298 milhões de dólares em vendas. Estes fatos mostram que a concentração foi expressiva e que se destacou frente aos outros ramos da atividade econômica, que também passaram por concentração, mas perderam postos entre as 50 maiores do país, ou seja, se este ramo da atividade passou a ocupar mais postos dentro do grupo, há clara indicação de que nele ocorreu maior concentração econômica.

A segunda lógica notória é a da centralização econômica, compreendida com resultado da aquisição de uma empresa por outra e/ou da diminuição do número de empresas que operam num dado ramo ou setor, revelando centralização na decisão e tendência à oligopolização. No interregno tomado como referência (2005 a 2015), houve fusões e aquisições no ramo do comércio varejista. $\bigcirc$ Grupo Pão de Açúcar recebeu investimentos elevados do grupo francês Casino, em 2005, tornando-se uma empresa franco-brasileira e passando à frente do grupo Carrefour, também de capital francês, que vinha ocupando sempre a primeira posição do varejo no país.

Em 2013, foi aprovada a fusão de duas grandes empresas do ramo de comercialização de eletrodomésticos do país - Casas Bahia e Pontofrio - que passaram a integrar, junto com a rede Bartira, a Via Varejo (16a no ranking de 2015). ${ }^{9}$ Esta, por sua vez, no mesmo ano, passou a ser controlada pelo Grupo Pão de Açúcar (o $13 \circ$ no mesmo ranking). ${ }^{10}$ Assim, a centralização econômica foi enorme no ramo do comércio varejista.

Para reforçar a tendência, temos ainda o exemplo do Grupo Atacadão (170 do ranking) que foi adquirido pelo Grupo Carrefour em 2007 (Atacadão, [s.d.]).

A lógica que orienta a concentração econômica e a centralização econômica não pode ser vista sem se considerar o modo que essas empresas passaram a se organizar no espaço. Todas elas ampliaram a cobertura espacial, ou seja, promoveram em alguma medida desconcentração espacial, e esta lógica, de natureza espacial, deve ser igualmente vista como uma tendência geral do capitalismo. No Brasil, as maiores empresas comerciais (sobretudo as do autosserviço alimentar), mas não somente elas), estavam prevalentemente em metrópoles nacionais e regionais, e em grandes cidades, mas passaram progressivamente a buscar os mercados

7 As empresas e suas posições no ranking: Carrefour (14a), Casas Bahia (15a) e Grupo Pão de Açúcar (18a).

8 As empresas e suas posições no ranking: Grupo Pão de Açúcar (13a), Via Varejo (16a), Atacadão (17a), Walmart Brasil (27a), Carrefour (30a) e Lojas Americanas (50a).

9 Segundo o site da empresa, a Via Varejo ([s.d.]) está em 400 municípios brasileiros, 20 estados e no Distrito Federal, com mais de 900 lojas e cerca de 50 mil funcionários.

10 O grupo é composto hoje de lojas em vários segmentos e marcas: (a) Multivarejo: Pão de Açúcar, Extra, Minuto Pão de Açúcar, Minimercado Extra, Qualitá, Taeq, Casino, Club des Sommerliers, Finlandek e Caras do Brasil; (b) Atacado de autosserviço: Assaí Atacadista; (c) Via Varejo: Casas Bahia, Pontofrio e Móveis Bartira; (d) e-commerce: Cnova, com os sites Extra.com.br, Pontofrio.com, CasasBahia.com.br, Barateiro.com, PartiuViagens.com.br, Cdiscount.com, além das soluções B2B por meio da plataforma eHub.com.br, e do Pontofrio Atacado, (e) GPA Malls, responsável pela gestão dos ativos imobiliários do GPA ([s.d.]), administração e expansão das galerias comerciais. 
das cidades médias com importantes papéis regionais. Esta lógica - desconcentração espacial - acompanhou-se do aumento do número de unidades nas cidades em que elas já operavam, mas em vários casos a expansão territorial foi muito expressiva. $\bigcirc$ Mapa 1 , relativo às mais importantes empresas do abastecimento alimentar, revela a lógica de desconcentração espacial que viabilizou o crescimento delas.

\section{Mapa 1 - Mais importantes empresas do abastecimento alimentar, 2016}

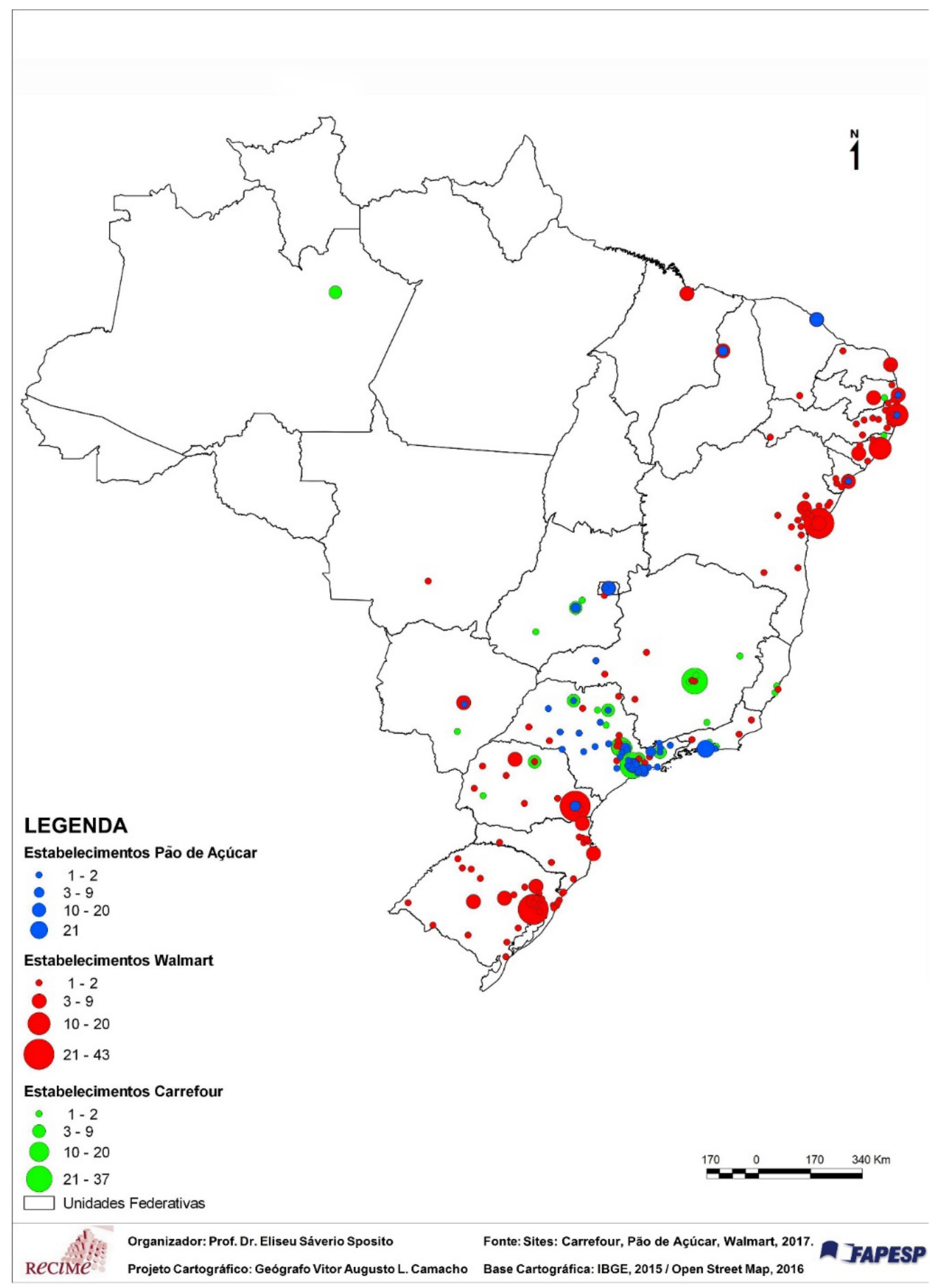


Embora o grupo Pão de Açúcar permaneça com localização predominante nas metrópoles e capitais do país, no estado de São Paulo, já é notória sua expansão pelas cidades médias mais importantes. No caso do grupo Walmart, é significativa sua opção de buscar os mercados regionais comandados pelas cidades médias mais importantes, tanto no Nordeste como no Sudeste e no Sul do país. A rede Carrefour foi a primeira que buscou localizações em áreas de expansão capitalista mais recente: no Norte e no Centro-Oeste, mas não exclusivamente nas maiores cidades dessas regiões.

Acompanham-se as lógicas de concentração e centralização econômicas, e a de desconcentração espacial, de uma quarta lógica que é a de centralização espacial do capital, visto que o comando da quase totalidade destas empresas, na escala nacional, está em São Paulo, a principal metrópole do país. São justamente os que, hoje, estão sob o domínio do capital internacional ou em sociedade com eles. As sedes dos Grupos Carrefour (ao qual pertence o Atacadão) e Casino (sócio majoritário do Grupo Pão de Açúcar) estão na França, Walmart nos EUA e Makro na Holanda. " Entre as seis empresas citadas como as varejistas que pertencem às 50 maiores do país, ${ }^{12}$ apenas as Lojas Americanas são totalmente de capital brasileiro, e sua sede está na segunda maior metrópole do país: o Rio de Janeiro.

Por fim, sintetizando as outras quatro lógicas a que fizemos referência, destacamos que elas podem ser vistas por meio da articulação entre escalas geográficas, já tratada por vários autores, entre os quais destacamos Lacoste (1988), Corrêa (1997), Castro (1999, 2014), Brenner (2001, 2013), Sposito (2006, 2011), Melazzo e Castro (2008), Catelan (2013) e M. Souza (2013).

Essa lógica não é recente, visto que, desde a passagem do modo feudal de produção para o capitalista de produção, no período mercantil, iniciaram-se ações que mostram historicamente que países e empresas buscaram ampliar a cobertura espacial de extração de riqueza e de realização comercial. Davam início, assim, à conformação de um sistema-mundo, nos termos expostos por Olivier Dolfuss, o que claramente denota a tendência à internacionalização da economia e das sociedades. $\bigcirc$ que há a ser considerado é o modo como esta internacionalização se realiza no período atual: o movimento entre empresas e agentes, que operam em diferentes escalas geográficas, realiza-se apoiada em tecnologias de informação e comunicação que aceleram as possibilidades de reprodução capitalista, de deslocamento de riqueza entre territórios e de extração de mais valia numa escala e num ritmo (espaço-tempo) nunca alcançados anteriormente. Ora, as rápidas descrições feitas sobre as quatro primeiras lógicas descritas nesta seção indicam claramente como empresas "saltam escalas" e tentam se impor como hegemônicas (sem nunca atingir isso completamente), mas impondo padrões de consumo e fazendo escolhas espaciais que redefinem a estrutura espacial dos sistemas urbanos e o acontecer da vida urbana.

No plano econômico ou no plano espacial, buscamos mostrar as lógicas que prevalecem no período atual. Elas revelam tendências importantes, mas podemos também compreender que face à concorrência, em que pese a oligopolização observada no setor do varejo, outras empresas podem desenvolver estratégias (sempre subordinadas às lógicas gerais) que têm como objetivo alcançar nichos de mercado ou áreas geográficas em que ainda não estão presentes as maiores.

11 Embora não conste entre as 50 maiores que operam no país no ranking relativo a 2015, o Makro foi incluído na análise por sua importância crescente no Brasil e na escala internacional.

12 As empresas e suas posições no ranking: Carrefour (14a), Casas Bahia (15a) e Grupo Pão de Açúcar (18a). 


\section{Estratégias espaciais}

$\bigcirc$ par dialético para nossa interpretação, como destacado, é composto pelas lógicas e pelas estratégias das empresas. Como ocorre com a palavra lógica, a palavra estratégia é carregada de diversos sentidos podendo ser vista, também, como polissêmica. De origem grega (strategos) significa, de um modo geral, a forma como os agentes se organizam para atingir uma meta, e foi utilizado, inicialmente, no âmbito militar (em outras palavras, é a ação do general nos conflitos). Atualmente, ela pode ser aplicada à tomada de decisão das empresas (em qualquer ramo de atividade econômica) para localizar sua sede ou seus estabelecimentos; às artimanhas para a criação de mercados específicos; aos relacionamentos com outras empresas ou às formas de tratar as relações entre elas e os clientes etc. Enfim, é uma palavra que pode conotar diferentes formas de ação de um agente econômico que carrega, em seu âmago, o peso da tomada de decisões (diferentemente da lógica, que contém o significado dos processos gerais que envolvem e condicionam as estratégias).

Foi feita uma busca, ${ }^{13}$ por meio de palavras chave semelhantes (spatial strategies e spatial strategy), e foram encontrados vários textos que continham essas expressões. A fonte principal foi o Google Acadêmico, e o objetivo era compreender como as estratégias espaciais poderiam ser associadas às iniciativas das empresas nas suas tomadas de decisão para suas ações. Num segundo momento, priorizamos encontrar os textos que desenvolviam tais expressões. Vários autores compõem o grupo que tem, de maneira explícita, a preocupação com as estratégias espaciais: Laulajainen (1987), Clark (1989), Clark, Feldman e Gertler (2000), Martin (2000), Sheppard (2000), Fischer (2003), Levy e Lussault (2003), Markusen (2006), McDowell (2006), Bennett (2009), Christopherson (2007), Chapman (2009), Rutherford (2009), Smith (2009), Derudder (2009), Miguel (2015), entre muitos outros. Vamos estabelecer nosso diálogo com alguns entre os autores selecionados.

Fischer (2003) afirma que:

[...] para as grandes empresas, o paradigma de referência, no que diz respeito à estratégia espacial, é aquele da "rentabilidade do espaço": a escolha pelo local de implantação depende das capacidades do meio em satisfazer as exigências de funcionamento da empresa, permitindo-lhe ao mesmo tempo minimizar os seus custos de localização e de produção e otimizar seus benefícios (de toda natureza). Estas estratégias espaciais acabam inevitavelmente sendo muito seletivas e, geralmente, benéficas para os pontos fortes dos territórios (Fischer, 2003, p. 14).

autor incorpora, em sua abordagem de estratégia, seu caráter espacial e dá atenção às dinâmicas das empresas e suas possibilidades de definição da localização de seus estabelecimentos de maneira seletiva com o objetivo principal que é a otimização de seus benefícios (lucros), privilegiando certas parcelas do território. Portanto, quando tratamos da localização dos estabelecimentos comerciais e de serviços nas cidades médias, muitas grandes empresas, ainda que obedecendo às lógicas espaciais que orientam, de modo geral, suas ações, terão que desenvolver estratégias espaciais particulares a cada contexto espaço-temporal, sempre con-

13 Agradecemos o apoio do Prof. Dr. Cleverson Alexsander Reolon, da Universidade Estadual de Maringá, membro da equipe do projeto temático já citado, que fez esse levantamento. 
siderando os campos de concorrência em que se inserem. Os menores tamanhos do mercado (comparados aos metropolitanos) e/ou os papéis regionais distintos que exercem (em termos de alcance espacial e de poder de compra), e/ou, ainda, a situação geográfica delas (mais ou menos perto de outras cidades de mesmo ou de maior porte e importância regional) são condicionantes que exigirão escolhas locacionais muito singulares, resultados de estratégicas espaciais. Combinarão decisões que se estabelecem na escala da rede urbana com aquelas que se estabelecem na escala da cidade.

Contribuindo também para a compreensão de estratégia espacial, Bennett (2009, p. 170, traduções nossas) afirma que alterar "a estrutura espacial da firma é uma maneira de gerir [...] riscos (tanto antes como depois de terem surgido)". Por isso, "uma estrutura espacial descentralizada, especialmente quando diferentes instalações de produção atendem diferentes mercados, pode reduzir os riscos de flutuações da oferta e da procura por meio da diversificação e ajudar a estabilizar as receitas por meio da firma como um todo". Em outra perspectiva, "pode levar, também, a um aumento dos custos de transação e dificuldades em monitorar o comportamento de gestores espacialmente dispersos". Nesse caso, a "relocalização também pode ser uma opção para lidar com as difíceis condições de mercado que já surgiram, onde existe a opção de mudar para áreas de trabalho potencialmente mais barato e custos regulatórios [mais interessantes para a empresa], e/ou uma maior produtividade".

Como trabalhamos na perspectiva de compreender a rede urbana em diferentes escalas, quando se trata da rede urbana global, lembramos que, para Derudder (2009, p. 265, tradução nossa):

A rede global de cidades, então, é criada principalmente através da transnacional, cidade que centraliza as firmas produtoras de estratégias espaciais de serviços, uma ideia tomada e estendida posteriormente por Peter Taylor e seus colegas de seu grupo na rede Globalização e Cidades Mundiais (GaWC). Sua alegação é que as firmas produtoras de serviços criaram em todo o mundo redes de escritórios que cobrem as principais cidades da maioria ou em todas as regiões do mundo, e isso é exatamente a miríade de conexões entre estes complexos de serviços que dão lugar à formação de uma rede urbana transnacional.

Sheppard (2000, p. 101, tradução nossa), por sua vez, "procura examinar as estratégias de localização e consequências não intencionais de capitalistas em uma economia composta de diferentes classes de atores com objetivos econômicos conflitantes".

Uma ideia importante que assumimos neste texto é aquela exposta por Clark, Feldman e Gertler (2000). Para eles:

[...] assumindo [que] todos os mercados são acessíveis, as empresas podem desenvolver estratégias mistas de localização; maiores mercados são altamente contestados, levando produtores rivais a localizar de maneira a facilitar suas estratégias competitivas enquanto os mercados menores são menos contestados, sendo dominados tanto por produtores locais como produtores distantes que dependem de acessibilidade de transportes (Clark; Feldman; Gertler, 2000, p. 12, tradução nossa). 
Mesmo quando analisa o papel da produção industrial, Fischer (1994) dá pistas para compreender as estratégias de localização das empresas, por um lado, e dos estabelecimentos, por outro. No que concerne às empresas e suas relações no território, ele destaca que formam redes estruturadas pelos fluxos de bens, serviços e materiais, fluxos monetários e as relações mercantis; neste caso, destaca-se o papel dos mercados (financeiro, comercial, de bens e serviços e de trabalho) visando seu crescimento. As estratégias são definidas, certamente, tomando-se em consideração as lógicas econômicas e espaciais que norteiam a ação das empresas.

No caso das grandes empresas, a tomada de decisão para a implantação de novas unidades leva em consideração, entre vários fatores, a conjuntura de mercado num dado momento. Isso aponta o mapeamento da clientela e sua divisão entre as empresas que dominam o mercado. Primeiramente, a tendência é de compra ou de fusão de empresas de igual porte ou menores, como já descrito na seção anterior do texto. Isso não significa que as pequenas e médias empresas desapareçam do mercado: ao contrário, muitas estabelecem suas estratégias de sobrevivência de acordo com sua capacidade de competir na rede urbana ou nos diferentes espaços da cidade, seja ela de nível metropolitano ou de intermediação na rede urbana.

O Mapa 2 mostra a localização dos pontos de venda de três grupos econômicos voltados para o comércio varejista. Tomando como referência o modo como fazem escolhas na escala da rede urbana, um exemplo que merece atenção é o Grupo Zema, que atualmente opera com o ramo comercial de eletrodomésticos, um dos mais fortemente oligopolizados frente à fusão de duas redes importantes - Casas Bahia e Pontofrio - e a presença de uma terceira, a Magazine Luiza. ${ }^{14}$

Grupo Zema é original de Araxá-MG e surgiu no ano de 1923, tendo passado a operar no ramo na década de 1970. Por meio do Mapa 2, verificamos que a rede tem importância significativa no norte do estado de São Paulo e definiu as cidades pequenas como territórios para ampliar sua rede de lojas, chegando, no máximo, a cidades de porte intermediário, sem ir para outras áreas do estado, como o oeste, o centro ou as proximidades da área metropolitana de São Paulo. $\bigcirc$ grupo tem lojas para venda de eletrodomésticos, mas mantém parte de suas atividades de origem, como a distribuição de combustíveis e, para ampliar sua atuação, passou a vender calçados e confecções de diversas marcas, tanto para o público masculino quanto para o feminino.

Esse exemplo mostra a articulação das lógicas econômicas com as estratégias espaciais: ampliação do número de lojas, diversificação de ramos de atuação e ampliação das linhas de produtos vendidos. A diversificação dos negócios mostra preocupação em atuar em diferentes ramos do comércio visando sustentar o grupo de acordo com as variações conjunturais da economia. A atuação territorial do grupo, privilegiando cidades pequenas e médias do estado de Minas Gerais e de estados limítrofes (São Paulo, Goiás, Bahia, Espírito Santo e Mato Grosso do Sul), levou à decisão de constituir um centro de distribuição comercial em Montes Claros, no norte de Minas Gerais. Nesse exemplo, as estratégias espaciais adotadas visam enfrentar a concorrência das maiores empresas por meio da escolha de cidades que não são alvos delas.

14 Ocupa a 57a posição, relativamente ao ano de 2015, no ranking já citado, com 2.378 milhões de dólares em vendas. Segundo o site da empresa (Magazine Luiza, [s.d.]), a rede tem mais de 740 lojas no país. 


\section{Mapa 2 - Exemplo de localização das empresas no estado de São Paulo: grupos Zema, Magazine Luiza e Pontofrio, 2016}

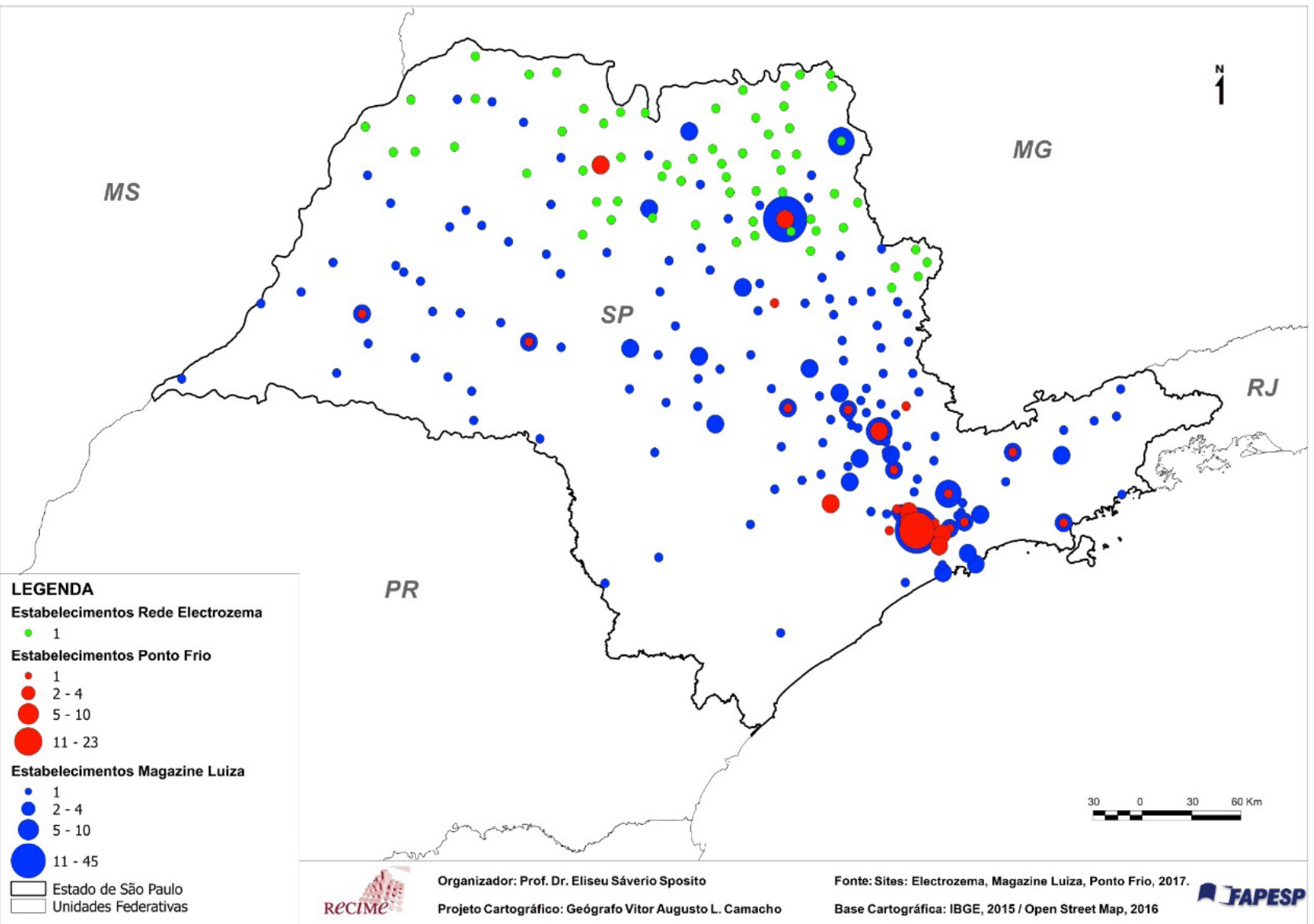

Exemplo diferente é o do Magazine Luiza. A distribuição de suas lojas obedece, aparentemente, ao critério da hierarquia urbana e desse ponto de vista, poderia ser vista como mais designativo dos conjuntos de lógicas gerais já descritas anteriormente. Tem maior número de lojas no município de São Paulo, apresenta concentração na área metropolitana comandada por esta cidade e, num segundo plano, na área densamente urbanizada de Campinas. Em seguida, a concentração é em Ribeirão Preto e cidades próximas. Numa relação quantitativa evidente, as cidades médias do interior do estado contam com lojas e mesmo cidades pequenas também têm a presença de unidades da rede. Assim, as áreas de maior concentração urbana têm mais lojas, e a rede urbana é contemplada em todo o estado com a presença da rede, com exceção do Vale do Ribeira, no sul do estado de São Paulo. Entretanto, para passar do plano da lógica geral e avaliar as estratégias que a empresa adotou, é importante destacar que essa rede iniciou suas operações em Franca, cidade média do estado, em 1957. Amplia sua atuação na escala regional, monta nos anos de $1990 \mathrm{seu}$ primeiro centro distribuidor, também numa cidade média, Ribeirão Preto. A partir dos anos 2000 entra no comércio eletrônico e amplia de modo mais importante, o número de filiais, alcançado a escala nacional, tendo no período adquirido 13 outras empresas menores que ela.

Um terceiro exemplo é a Rede Pontofrio, já citada. Desde sua fusão com as Casas Bahia e, em seguida, a aquisição das duas pelo Grupo Pão de Açúcar, para evitar a concorrência entre empresas do mesmo grupo, as tomadas de decisão vem se voltando à conquis- 
ta dos mercados de maior poder aquisitivo, tanto pela linha de produtos que comercializa, quanto pelas escolhas locacionais que efetua na escala das cidades, como, ainda, pela relevância que dá ao comércio eletrônico. Face a estes fatores, a presença física de lojas do grupo configura, no estado de São Paulo, uma rede que privilegia a metrópole e as cidades médias com maior importância. Assim, sua distribuição territorial é seletiva e evidencia a importância do tamanho das cidades onde se localiza.

Esses três exemplos foram tomados para mostrar diferentes estratégias espaciais de estabelecimentos de comércio no estado de São Paulo. Eles ilustram a situação de um grupo que privilegia a concentração da população em cidades médias e na metrópole (Pontofrio); outro que se desenha de acordo com a hierarquia urbana (Magazine Luiza), marcando presença em muitos municípios, mostrando proporção desde a metrópole até cidades pequenas, com número aparentemente proporcional de estabelecimentos; e, por fim, um grupo que prefere se estabelecer em cidades pequenas, diversificando suas atividades de comércio (Grupo Zema). Por outro lado, todos os grupos seguem as mesmas cinco lógicas econômicas e espaciais descritas na segunda seção deste texto, ainda que no decorrer do tempo, objetivando-as, tais empresas desenvolvam estratégias espaciais que diferente entre si, com distribuição dos estabelecimentos de acordo com as conveniências induzidas pelas escolhas locacionais mais adequadas a cada situação.

\section{Considerações finais}

As lógicas econômicas e espaciais, de um lado, e as estratégias espaciais, de outro, formam um par contraditório que contribui para explicar, de maneira racional, como as empresas atuam espacialmente e como decidem suas localizações na rede urbana, seja do ponto de vista de um país ou entre países (isto é, em diferentes escalas geográficas). Elas não foram vistas, neste texto, separadamente, apesar de cada análise ter sido vista numa seção do texto. Sua importância foi vista por meio de diferentes exemplos, num momento de mundialização da economia, de hegemonia de um período econômico chamado pós-fordista que, por sua vez, condiciona as formas de consumo, sob a égide de valores e tomadas de decisão neoliberais. Esses exemplos seguem a lógica capitalista de potencializar o espaço para seus negócios visando ampliar os lucros nas vendas, mas tomam decisões de localização de suas unidades de acordo com estratégias espaciais diferentes, tornando suas tomadas de decisão os aspectos empíricos que sustentam a interpretação teórica.

Acreditamos que, depois de mostrar detalhadamente como se compõe cada um desses conceitos e como eles se desdobram em diferentes composições de empresas, pudemos explicar como, partindo das mudanças potenciais no consumo da população brasileira (em suas diferentes possibilidades), a motivação da atuação das empresas de comércio varejista tem suas implicações diretas na rede urbana. Isso se dá ampliando o movimento de articulação entre escalas geográficas, lógica espacial e, ao mesmo tempo, ferramenta metodológica que consideramos fundamental para analisar as especificidades do período atual. 


\section{Referências}

ATACADÃO. Disponível em: https://www.atacadao.com.br/historia. Acesso em: 25 ago. 2016.

BENNETT, P. Financial Risks and Management. In: KITCHIN, R.; THRIFT, N. (Ed.). International Encyclopedia of Human Geography. Amsterdam: Elsevier, 2009. p. 167-172. v. 4.

BRENNER, N. Reestruturação, reescalonamento e a questão urbana. Tradução de Daniel Sanfelici, Karen Heberle. Geousp - Espaço e Tempo (Online), São Paulo, n. 33, p. 198-220, 2013. ISSN 2179-0892. Disponível em: http://www.revistas.usp.br/geousp/ article/view/74311/77954. Acesso em: 20 jun. 2017.

. The limits to scale? Methodological reflections on scalar structuration. Progress in Human Geography, v. 25, n. 4, p. 591-614, 2001.

CASTRO, I. E. Escala e pesquisa na geografia: problema ou solução?. Espaço Aberto, Rio de Janeiro, v. 4, n. 1, p. 87-99, 2014.

problema da escala. In: CASTRO, I. E. et al. (Org.). Geografia: conceitos e temas. Rio de Janeiro: Bertrand Brasil, 1999. p. 117-140.

CATELAN, M. J. Heterarquia urbana: interações espaciais interescalares e cidades médias. São Paulo: Cultura Acadêmica, 2013.

CHAPMAN, K. Industrial Location. In: KITCHIN, R.; THRIFT, N. (Ed.). International Encyclopedia of Human Geography. Amsterdam: Elsevier, 2009. p. 396-401. v. 5 .

CHRISTOPHERSON, S.; CLARK, J. Remaking Regional Economies: Power, labor, and firm strategies in the knowledge economy. Abingdon: Taylor E Francis, 2007.

CLARK, G. L. Unions and communities under siege: American communities and the crisis of organized labor. New York: Cambridge University Press, 1989.

; FELDMAN, M. P.; GERTLER, M. S. Economic Geography: transition and Growth. In: CLARK, G. L.; FELDMAN, M. P.; GERTLER, M. S. (Ed.). The Oxford Handbook of Economic Geography. Oxford: Oxford University Press, 2000. p. 3-17.

CORREAA, R. L. Trajetórias geográficas. Rio de Janeiro: Bertrand Brasil, 1997.

DARDOT, P.; LAVAL, C. A nova razão do mundo: ensaio sobre a sociedade neoliberal. São Paulo: Boitempo, 2016[2009].

DERUDDER, B. World/Global Cities. In: KITCHIN, R.; THRIFT, N. (Ed.). International Encyclopedia of Human Geography. Amsterdam: Elsevier, 2009. p. 262-268. v. 12.

EXAME. Melhores e maiores: as 500 maiores empresas do Brasil. São Paulo: Abril, jul. 2006. Disponível em: https://issuu.com/exame/docs/mm2006. Acesso em: 25 ago. 2016.

FISCHER, A. A dimensão espacial no "aménagement" do território: o exemplo francês. Re- 
vista RA'E GA, Curitiba, n. 7, p. 9-17, 2003.

Industrie et espace géographique. Paris: Masson, 1994.

GPA. Disponível em: http://www.gpabr.com/o-grupo/o-grupo.htm. Acesso em: 15 ago. 2016

HIDALGO, R. et al. En las costas del neoliberalismo: naturaleza, urbanización y producción inmobiliaria: experiencias en Chile y Argentina. Santiago: PUC-Chile, 2016.

LACOSTE, Y. A geografia, isso serve antes de mais nada para fazer a guerra. Campinas: Papirus, 1988.

LAULAJAINEN, R. Spatial strategies in retailing. Dordrecht: D. Reidel, 1987.

LAZZARATO, M. La fábrica del hombre endeudado: ensayo sobre la condición neoliberal. Buenos Aires: Amarrortu, 2013[2011].

LEVY, J.; LUSSAULT, M. Dictionnaire de la géographie: et de l'espace des sociétés. Paris: Belin, 2003.

LIPOVETSKY, G.; SERROY, J. La cultura-mundo: respuesta a una sociedad desorientada. Barcelona: Anagrama, 2010.

LOZANO, L. P. G.; SPOSITO, E. S. Cidades médias e distribuição espacial do comércio de eletrodomésticos no Brasil. In: BELLET, C. et al. (Org.). Urbanización, producción y consumo en ciudades medias/intermedias. Lleida: Edicions de la Universitat de Lleida, 2015. p. 79-106.

MAGAZINE LUIZA. Disponível em: http://www.magazineluiza.com.br/quem-somos/perfil-da-empresa/. Acesso em: 25 ago. 2016.

MARKUSEN, A. Economic geography and political economy. In: BAGCHI-SEN; S.; SMITH, H. L. (Ed.). Economic Geography: past, present and future. New York: Taylor E Francis, 2006. p. 94-102.

MARTIN, R. L. Local Labour Markets: their Nature, Performance, and Regulation. In: CLARK, G. L.; FELDMAN, M. P.; GERTLER, M. S. (Ed.). The Oxford Handbook of Economic Geography. Oxford: Oxford University Press, 2000. p. 455-476.

McDOWELL, L. Feminist economic geographies gendered identities, cultural economies and economic change. In: BAGCHI-SEN, S.; SMITH, H. L. (Ed.). Economic Geography: past, present and future. New York: Taylor E Francis, 2006. p. 34-46.

MELAZZO, E. S.; CASTRO, C. A escala geográfica: noção, conceito ou teoria?. Terra Livre, v. 2, n. 30, p. 133-142, 2008.

MIGUEL, F. M. Geografía económica (aplicada)/geografia econômica/economic geography. In: TRIGAL, L. L.; FERNANDES, J. A. R.; SPOSITO, E. S. (Org.). Diccionario de geografía aplicada y profesional: terminología de análisis, planificación y gestión del territorio. León: Universidad de León, 2015. p. 270-271.

RUTHERFORD, J. Informational City. In: KITCHIN, R.; THRIFT, N. (Ed.). International 
Encyclopedia of Human Geography. Amsterdam: Elsevier, 2009. p. 475-480. v. 5 .

SHEPPARD, E. Geography or Economics?: Conceptions of Space, Time, Interdependence, and Agency. In: CLARK, G. L.; FELDMAN, M. P.; GERTLER, M. S. (Ed.). The Oxford Handbook of Economic Geography. Oxford: Oxford University Press, 2000. p. 99-119.

SMITH, A. Spatial Division of Labor. In: KITCHIN, R.; THRIFT, N. (Ed.). International Encyclopedia of Human Geography. Amsterdam: Elsevier, 2009. p. 348-354. v. 10 .

SOJA, E. W. Geografias pós-modernas: a reafirmação do espaço na teoria social crítica. Rio de Janeiro: Jorge Zahar, 1993.

SPOSITO, M. E. B. A produção do espaço urbano: escalas, diferenças e desigualdades socioespaciais. In: CARLOS, A. F. A. et al. A produção do espaço urbano: agentes e processos, escalas e desafios. São Paulo: Contexto, 2011. p. 123-145.

. O desafio metodológico da abordagem interescalar no estudo das cidades médias no mundo contemporâneo. Cidades, Presidente Prudente, v. 3, p. 143-157, 2006.

SOUZA, M. L. Os conceitos fundamentais da pesquisa socioespacial. Rio de Janeiro, Bertrand Brasil, 2013.

SOUZA, J. A construção social da subcidadania: para uma sociologia política da modernidade periférica. Belo Horizonte/Rio de Janeiro: UFMG/luperj, 2006.

VIA VAREJO. Disponível em: http://ri.viavarejo.com.br/conteudo_pt.asp. Acesso em: 15 ago. 2016. 